12. Короленко Р.Н., Авраменко А.А. Частота выявления активной формы хеликобактерной инфекции у больных хроническим неатрофическим гастритом с различными формами дискинезии желчевыводящих путей. Український журнал медищини, біологї та cпорту. 2019. Том 4, № 2(18). С.136 - 141 .

13. Спосіб тестування гелікобактерної інфекції у хворих на хронічний гелікобактеріоз за допомогою ХЕЛІК-тесту: пат. 128945 Україна: МПК GO1N 33/497(2006.01), A61B 5/091(2006.01). № 2018 05050; заявл. 07.05.2018; опубл. 10.10.2018, Бюл. № 19. 3 с.

14. Степанов Ю.М., Будзак И.Я. Маастрихтский консенсус - 5: аналитический обзор положений. Гастроентерологія. 2017.Том 51, № 1 . С. $36-45$.

DOI https://doi.org/10.30525/978-9934-26-182-4-2

\title{
МЕХАНИЧЕСКАЯ ПОДДЕРЖКА ГЕМОДИНАМИКИ У БОЛЬНЫХ С ПОСТИНФАРКТНЫМ РАЗРЫВОМ МЕЖЖЕЛУДОЧКОВОЙ ПЕРЕГОРОДКИ
}

\author{
Алиев Р. А. \\ кандидат медицинских наук, сердечно-сосудистый хирург, \\ заведующий отделением сердечно-сосудистой хирургии \\ Клиника «Зеферан» \\ г. Баку, Азербайджан
}

Груша М. М.

кандидат биологических наук, дочент кафедры биологии

Национальный медицинский университет имени А. А. Богомольиа г. Киев, Украина

\section{Введение.}

Разрыв межжелудочковой перегородки - это редкое, но в тоже время грозное осложнение острого инфаркта миокарда. Реперфузионная терапия позволила значительно снизить это осложнение. Однако при постинфарктных разрывах межжелудочковой перегородки (ПРМЖП) частота смертельных исходов неизменно высока. Без хирургического лечения внутригоспитальная смертность составляет $90 \%$ а при 
хирургическом лечении- 47 \% [1.2]. Сроки оперативного вмешательства, а также тактика преоперативной терапевтической подготовки этих пациентов остается спорным. На основании некоторых исследований рекомендуется ранняя (менее 3 дней) коррекция ПРМЖП [3.4], так как согласно статистике $40 \%$ больных с разрывами межжелудочковой перегородки попадают к врачу со стабильной гемодинамикой половина которых несмотря на консервативное лечение осложняются кардиогенным шоком [5]. Однако морфо - гистологические изменения пораженных тканей не только повышают сложность оперативного вмешательства, но и приводят к прорезыванию хирургических швов, что увеличивает число повторных разрывов межжелудочковой перегородки в послеоперационном периоде [6]. Поэтому выбор «золотой середины»отсрочка операции при помощи ІАВР считаем наиболее приемлемым.

В работе представлен ретроспективный анализ 90 больных ИБС, осложненной постинфарктным разрывом межжелудочковой перегородки (ПРМЖП), которые были прооперированы за период 2002-2019 гг. Мы попытались сгруппировать пациентов в предоперационном периоде в соответствии с классификацией острой сердечной недостаточности по Киллипу. При этом учитывались демографические данные, факты из истории болезни, эхокардиографические особенности, клиника и гемодинамика как в предоперационном периоде, так и интраоперационно. И самое главное учитывалась тактика ведения больных в предоперационном периоде

\section{Результаты:}

Средний возраст пациентов составил 59,9 \pm 9,59 лет. Из них 65 (72,2\%) мужчин и $25(27,7 \%)$ женщин. Пятнадцать $(16,6 \%)$ пациентов были курильщиками, 31 (34,4\%) диабетиками. У 70 (77,7\%) отмечалась гипертоническая болезнь. Подавляющее большинство больных находилось в III функциональном классе $62 \%$ \% со средней фракцией выброса $43,9 \pm 10,4 \%$. По результатам коронарографии однососудистое поражение коронарных артерий было выявлено 18 (20\%), двусосудистое поражение $32(35,5 \%)$ пациентов, трехсосудистое поражение у 40(44,4 \%) пациентов, Стволового поражения в нашей серии отмечено не было. Неотложная операция в первые сутки поступления в клинику была проведена 14 (15,6\%). Оперированных в первые 3 суток 21 (23,3\%). В первую неделю - 19(21,1 \%), В отдаленном периоде от 8 до 34 дней было прооперировано 29 (32,2 \%) больных. Среднее время от поступления до операции составило 7,8 \pm 7,7 дней.

Операции проводились с помощью стандартного искусственного кровообращения. К ПРМЖП подходили через зону инфаркта левого 
желудочка и правого предсердия у 81(97,6\%) и 2 (2,4\%) пациентов соответственно. Левая вентрикулотомия была выполнена разрезом инфарцированной зоны миокарда. Разрез проводился на расстоянии 2-3 см от левой передней нисходящей артерии или задней нисходящей артерии, в зависимости от места инфаркта миокарда. Пластика ПРМЖП была выполнена с использованием концепции «исключения инфаркта». Дефект был ликвидирован подшиванием аутоперикардиального лоскута, или ксенотрансплантанта (бычий перикард) или протеза (Dacron или Gore Tex), отдельными полипропиленовыми швами 3-0 с подпоркой, проходя через через здоровый миокард, поодаль от зоны инфаркта. Сопутствующие процедуры включали в себя аневризмэктомия 7(8,4\%), тромбэктомия $3(3,6 \%)$, АКШ у 12 (14,5\%) больных. Число шунтов составляло от 2 до 4, в среднем $1,2 \pm 0,5$. ЛВГА были использованы для шунтирования. ПМЖВ в 2 случаев. Во всех остальных случаях были использованы БПВ. Закрытие вентрикулотомии проводилось по Даггету в 17 (20,5\%), по Дэвиду в 1 (1,2\%), по Дор в 2 (2,4\%) случаях. Множественные ПРМП были у 3 (3,6\%) больных.

Детальный анализ группы с ВАБК: 20 из 90 (22,2\%) больных было установлено ВАБК. 8 (40\%) больных поступили в состоянии гемодинамического (кардиогенного) шока. Из них 5 (25\%) ВАБК был установлен на этапе до операции с целью поддержки гемодинамики. Всем остальным больным ВАБК был установлен внутриоперационно.

Демографический спектр данных больных представлен следующим образом: 16 (80\%) мужчин, 4 (20\%) женщин. В возрасте от 44 до 81, в среднем $61,6 \pm 10,0$. Время от начала приступа ИМ и до поступления в клинику составляло $6,2 \pm 4,7$ дней. У 5 (25\%) больных 1 сосудистое поражение, у 6 ((30\%) больных 2 х сосудистое поражение, у 9 (45\%) больных множественные сосудистые поражения, у 2 (10\%) больных отмечалась дисфункция митрального клапана II-III степени. Фракция выброса колебалась от 20 до 49, составляла в среднем 37,7士8,6: у 14 (70\%) больных был передний дефект, у 6 (30\%) - задний дефект.

Мы придерживались тактики отсроченного вмешательства, но с обязательным условием стабильности гемодинамики, с целью выжидания образования хоть какой-то фиброзной ткани в зоне границ ПРМЖП. Однако если отмечались признаки ухудшения состояния на фоне данной поддержки, то этих пациентов брали на неотложную операцию. Среднее время от поступления в клинику до операции составляло 4,1 3 ,3 дней. Из них 8 (40\%) больных оперировались в первые сутки после поступления, что говорит о тяжести состояния. 
Клиническая характеристика больных с постинфарктными разрывами межжелудочковой перегородки.

\begin{tabular}{|c|c|c|}
\hline & ВАБК & ПРМЖП \\
\hline Возраст & $61,6 \pm 10,0$ & $59,9 \pm 9,59$ \\
\hline Пол М & $16(80 \%)$ & $65(72,2 \%) /$ \\
Ж & $4(20 \%)$ & $25(27,7 \%)$ \\
\hline Курильщики & $7(35 \%)$ & $15(16,6 \%)$ \\
\hline Сахарный диабет & $4(20 \%)$ & $31(34,4 \%)$ \\
\hline Гипертоническая болезнь & $15(75 \%)$ & $70(77,7 \%)$ \\
\hline Локализация ИМ & \\
\hline Передняя стенка & $14(70 \%)$ & $47(52,2 \%)$ \\
\hline Нижняя/ боковая стенка & $6(30 \%)$ & $43(47,8 \%)$ \\
\hline $\begin{array}{c}\text { Левожелудочковая недостаточность по } \\
\text { Киллипу ІІІ-ІV }\end{array}$ & $14(70 \%)$ & $16(17,8 \%)$ \\
\hline
\end{tabular}

Среднее время АИК составляло $234,3 \pm 102,6$ мин., пережатия

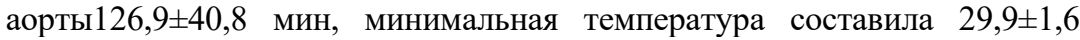
градусов. Больным, у которых ВАБК был установлен предоперационно, его останавливали на период АИК и включали на этапе согревания больного. 15 (75\%) больным ВАБК был установлен интраоперационно. В 1(5\%) случае не смогли выйти с АИК даже при высоких дозах инотропов и ВАБК и не сводя грудину, на центральной канюляции и аппарате ЭКМО перевели в отделение РИТ. Период поддержки ВАБК составлял от

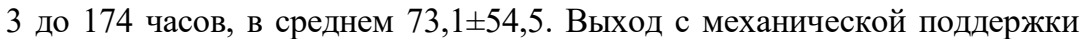
осуществлялся основываясь на стабильных показателях центральной гемодинамики - примерное АД 110/65 mmHg, ЧСС 90-100 уд. в мин (синусовый ритм), сохраненный темп диуреза, сатурация 96-99\% на спонтанном дыхании или через интубационную трубку, снижение инотропных средств до минимальной инотропной дозы, при одновременном снижении частоты контрпульсации с контролем функции клапанов сердца и отсутствие метаболического ацидоза. ВАБК переключался в режим 1:2, по прошествии 8-12 часов режим 1:4, про стабильных показателях- отключение и удаление баллона. Инотропная поддержка продолжалась в ОРИТ препаратами норадреналин 72,2 29,4 часов у $18((90 \%)$ больных, дофамин167,3 $\pm 81,4$ часов у 19 (95\%) больных, адреналин 39,4 5 ,4 часов у 12 (60\%) больных. 15 (75\%) пациентам требовалась инфузия 2-х и более инотропных средств. При анализе структуры осложнений и летальности мы решили исследовать влияние расположения дефекта и времени от разрыва - до операции на общую 
структуру. При анализе влияния временного фактора создали 3 группы 1экстренные операции (до 24 часов), 2-я до 7 дней, 3-я от 7 дней

Результаты выглядели следующим образом:

\begin{tabular}{|c|c|c|c|}
\hline$\overbrace{\text { Показатель }}^{\text {Групाп }}$ & $\begin{array}{c}\text { Группа 1 } \\
(\mathrm{n}=8(\mathbf{4 0 \%}))\end{array}$ & $\begin{array}{c}\text { Группа 2 } \\
(n=10(50 \%))\end{array}$ & $\begin{array}{c}\text { Группа 3 } \\
(\mathrm{n}=2(10 \%))\end{array}$ \\
\hline Период ИВЛ, час & $88,75 \pm 10,6$ & $33,7 \pm 20,34$ & $45 \pm 5,6$ \\
\hline Период ВАБК & $32,4 \pm 19,7$ & $86,7 \pm 59,1$ & $73,5 \pm 45,6$ \\
\hline $\begin{array}{c}\text { Инотропная } \\
\text { поддержка, n/\% }\end{array}$ & & & \\
\hline $\begin{array}{c}\text { Норадреналин, час } \\
\text { инфузии } \\
\end{array}$ & $62,7 \pm 8,3$ & $76,8 \pm 10,8$ & $61,5 \pm 28,9$ \\
\hline $\begin{array}{c}\text { Дофамин, час } \\
\text { инфузии }\end{array}$ & $33,3 \pm 22,1$ & $104,9 \pm 91,2$ & $88,5 \pm 67,2$ \\
\hline $\begin{array}{c}\text { Адреналин, час } \\
\text { инфузии }\end{array}$ & $64 \pm 42,4$ & $48,4 \pm 70,1$ & $22,5 \pm 17,7$ \\
\hline $\begin{array}{c}\text { Добутамин, час } \\
\text { инфузии }\end{array}$ & $104 \pm 89,6$ & $47,3 \pm 39,7$ & 43 \\
\hline $\begin{array}{l}\text { Отделяемое по } \\
\text { дренажам, мл }\end{array}$ & $2325 \pm 1378,8$ & $1417 \pm 448,4$ & $1890 \pm 155,6$ \\
\hline Смертность & $2(25 \%)$ & $2(20 \%)$ & $1(50 \%)$ \\
\hline
\end{tabular}

При анализе влияния места расположения ПРМЖП на структуру осложнений:

\begin{tabular}{|c|c|c|}
\hline Показатель & $\begin{array}{c}\text { Передние } \\
\text { (n=14/ 47) }\end{array}$ & $\begin{array}{c}\text { Задние } \\
(\mathbf{n = 6 / 4 3 )}\end{array}$ \\
\hline Период ИВЛ, час & $19,4 \pm 5,7$ & $65,66 \pm 89,7$ \\
\hline Период ВАБК, час & $73,1 \pm 54,5$ & $80,3 \pm 86,6$ \\
\hline Инотропная поддержка, n/\% & & \\
\hline Норадреналин, час инфузии & $72,2 \pm 89,4$ & $58,2 \pm 71,2$ \\
\hline Дофамин, час инфузии & $88,4 \pm 81,5$ & $68,2 \pm 58,4$ \\
\hline Адреналин, час инфузии & $39,4 \pm 53,4$ & $32 \pm 30,4$ \\
\hline Добутамин, час инфузии & $62,3 \pm 69,2$ & $96 \pm 10,4$ \\
\hline Отделяемое по дренажам, мл & $1635,5 \pm 1343,5$ & $696,7 \pm 312,7$ \\
\hline
\end{tabular}




\section{Обсуждение.}

Наше исследование показало, что отсроченное хирургическое лечение ПРМЖП, особенно после__ суток, сопровождается достоверным снижением летальности и осложнений. Использование ВАБК у больных с кардиогенным шоком (в нашем исследовании - 8 из 90 пациентов 8,8\%) позволяет стабилизировать этих больных, при прохождении гемодинамического коллапса [7], даже отсрочить хирургическое вмешательство [8].

При анализе групп достоверно отмечается что в группе больных с однососудистым поражением чаще требовалась ВАБК 5 б-х из 18 (27,7\%) против 18,75\%у больных с двухсосудистым и 22,5\% у больных с множественным поражением КА. При анализе осложнений и летальности довольно примечательно что больные оперированные в первые сутки требовали дольшей инотропной поддержки и отмечали больший процент летальных исходов. То же можно сказать и в отношении передних дефектов при ПРМЖП.

Даже не смотря на отсутствие доказательств рандомизированных исследований, ВАБК по сей день остается самым широко распространенным и действенным аппаратом механической поддержки гемодинамики [9]. Исследование İABP - SCHOK II, проведенные на 600 пациентах не показало выраженной разницы в смертности между группой, получившей лечение с применением ВАБК и группой не получившей такого лечения [10].

B исследовании CRISSP - AMI также не показало выраженного снижения размеров переднего инфаркта миокарда в группе с применением ВАБК и без [11]. На основании этих и подобных исследований в международных протоколах (руководствах) снизилась статистическая ценность рутинного использования контрпульсатора [12]. Несмотря на уменьшение частоты установки ВАБК в западных центрах, общее число больных нуждающихся в механической поддержке, остается стабильным. Это происходит за счет аппаратов ЭКМО и İMPELLA. Принимая во внимание, что последние используются только в крупных кардиохирургических центрах, то поддержка с помощью ВАБК все еще будет и должна быть во всех центах кардиологической помощи.

\section{Литература:}

1. Crenshaw BS, Granger CB, Birnbaum Y, Pieper KS, Morris DC, Kleiman NS, et al. Risk factors, angiographic patterns, and outcomes in patients with ventricular septal defect complicating acute myocardial infarction. 
GUSTO-I (Global Utilization of Streptokinase and TPA for Occluded Coronary Arteries) Trial Investigators, Circulation, 2000, vol. 101 (pg. 27-32)

2. Poulsen SH, Praestholm M, Munk K, Wierup P, Egeblad H, NielsenKudsk JE. Ventricular septal rupture complicating acute myocardial infarction: clinical characteristics and contemporary outcome. Ann Thorac Surg. 2008;85(5):1591-96.

3. Bouchart F, Bessou JP,Tabley A, Redonne M, Mouton-Schleifer D, Haas-Hubscher $\mathrm{C}$, et al. Urgent surgical repair of postinfarction ventricular septal rupture: early and late outcome. J Card Surg.1998; 13:104-12.

4. Sharma YP, Kamana NK, Vadivelu R. Precision in cardiology: should all cases of myocardial infarction with ventricular septal rupture require early repair? Heart Asia. 2013 Nov 19;5(1):235-7.

5. Копиця МП, Аболмасов ОМ, Литвин ОИ, Сакал ВВ. Механические осложнения острого инфаркта миокарда. Український терапевтичний журнал. 2013;1:108-12.

6. Deja MA, Szostek J, Widenka K, Szafron B, Spyt TJ, Hickey MS, et al. Post infarction ventricular septal defect - can we do better? Eur J Cardiothorac Surg. 2000;18:194-201.

7. Thiele H, Lauer B, Hambrecht $\mathrm{R}$, et al. Short-and long-term hemodynamic effects of intra-aortic balloon support in ventricular septal defect complicating acute myocardial infarction. Am J Cardiol. 2003;92:450-4.

8. Papalexopoulou N, Young CP, Attia RQ. What is the best timing of surgery in patients with post-infarct ventricular septal rupture? Interact Cardiovasc Thorac Surg. 2013;16:193-6.

9. Wernly, B., Seelmaier, C., Leistner, D. et al. Mechanical circulatory support with Impella versus intra-aortic balloon pump or medical treatment in cardiogenic shock-a critical appraisal of current data.Clin Res Cardiol 108, 1249-1257 (2019).

10. Thiele H, Schuler G, Neumann F-J, et al. Intraaortic balloon counterpulsation in acute myocardial infarction complicated by cardiogenic shock: design and rationale of the Intraaortic Balloon Pump in Cardiogenic Shock II (IABP-SHOCK II) trial. Am Heart J 2012; 163:938-945

11. Patel MR, Smalling RW, Thiele $\mathrm{H}$, et al. Intra-aortic balloon counterpulsation and infarct size in patients with acute anterior myocardial infarction without shock: the CRISP AMI randomized trial. JAMA 2011; 306:1329-1337

12. Alushi B, Douedari A, Froehlig G, et al. Impella versus IABP in acute myocardial infarction complicated by cardiogenic shock. Open Heart 2019;6: e000987. 